\title{
O paradoxo de Condorcet e a crise da democracia representativa
}

\author{
ISAAC EPSTEIN
}

“...Um costume habitual (entre os persas) é o de deliberar sobre assuntos importantes quando estão embriagados e, no dia seguinte, quando estão sóbrios, o dono da casa na qual a decisão foi tomada submete a deliberação à sua reconsideração. Se aprovada novamente, a decisão será executada, senão, é abandonada. Às vezes, no entanto, estão sóbrios em sua primeira deliberação, mas nestes casos, sempre reconsideram o assunto sob a influência do vinho...” Heródoto (484-425 aC), Livro chamado CLIO

“...A Democracia é uma forma de governo na qual os cidadãos distribuem os cargos estatais entre si por sorteio, enquanto na Oligarquia a qualificação é por propriedade e na Aristocracia, por educação...” Aristóteles (384-322 aC), Retórica $\left(1365^{\mathrm{b}}\right)$

“....Nas eleições procedia-se da seguinte forma: Algumas pessoas selecionadas da população eram encerradas num quarto perto do lugar onde se procedia à eleição, de tal forma que não eram vistas nem podiam ver ninguém, mas apenas podiam ouvir o ruído da assembléia que ocorria em local próximo. A decisão sobre as eleições, assim como sobre outros assuntos, eram tomadas em proporção ao volume dos gritos dos eleitores reunidos em assembléia. Os competidores não eram apresentados em conjunto, mas um após o outro e passavam em silêncio pela assembléia. Aqueles encerrados no quarto ao lado possuíam tabuinhas de escrever consigo e iam anotando, sem saber qual o candidato que estava passando, a intensidade do volume respectivo dos gritos da assembléia. Apenas anotavam quem passava em primeiro lugar, em segundo, terceiro, quarto etc... Aquele que tinha recebido a aclamação mais ruidosa era declarado senador devidamente eleito...". Plutarco (350-430 dC), A Vida de Licurgo (Eleições em Esparta)

“...Os membros do conselho dos 500 (de Atenas) eram selecionados por sorteio entre todos os cidadãos com mais de 30 anos. Seus mandatos eram de um ano e um homem só podia servir no Conselho duas vezes em toda sua vida. Quase todos os funcionários eram também escolhidos por sorteio a marca registrada da democracia para os gregos, e estavam limitados a um único ano no cargo não renovável - com exceção dos estrategos (strategoi) e outros cargos ad hoc como embaixadores, e possivelmente, alguns dos mais altos cargos..." Finlay, M.I., A Política no Mundo Antigo (Zahar, 1985:89)

A QUESTÃO DA aferição das decisões de um grupo, de uma comunidade ou mesmo da totalidade de uma população, em função das preferências individuais, articula-se intimamente à própria conceituação do que se costuma chamar de regime democrático.

Desde as normas da Carta Magna de um país, até os regimentos ou regras explícitas que regulam a vida das diversas comunidades, como as constituídas por 
acionistas das sociedades anônimas, sócios de um clube recreativo, assembléia de condôminos ou até mesmo pequenos grupos informais, o voto é a instância derradeira que pode dirimir de maneira aceitável, todos os conflitos com relação às decisões a serem tomadas, senão pelo consenso, pelo menos através da vontade da maioria dos interessados. Este procedimento de se aferir a vontade coletiva através do cômputo das preferências individuais, é o que se convenciona chamar, em linguagem comum, de democrático.

A partir da teoria clássica ou aristotélica das três formas de governo a Democracia - como o governo de todos os cidadãos - distinta da Monarquia - como governo de um só - e da Aristocracia - como o governo dos melhores - torna-se imprescindível, no governo democrático, fundamentar e legitimar os meios de se aferir a opinião ou a vontade da coletividade (1).

Os procedimentos que orientam a coleta das opiniões individuais para a composição da decisão da coletividade são, em geral, codificados cultural e socialmente e poderiam ser tema da antropologia social ou da história dos povos mas do qual não será possível nos ocuparmos aqui.

Para Rousseau (no Contrato Social), a Assembléia na qual se reúnem todos os cidadãos é a única soberana e a sua decisão é a vontade geral. Mas, como o aval desta vontade geral é a unanimidade, que por sua vez é bastante rara, é necessário confiar na vontade da maioria, que, sem ser necessariamente a de todos, é estabelecida segundo aquela vontade.

A noção de decisão coletiva nasce da distinção entre as decisões provenientes de uma coletividade, e as decisões individuais, pelas quais o indivíduo decide por si. Mas se uma pessoa decide por todos (como se fosse um ditador), pode se dizer que ocorre uma decisão coletiva, pondo-se à parte a questão de se saber se a decisão desta pessoa afere ou não a soma ou mesmo a maioria das preferências individuais.

Existem, porém, diferenças pragmáticas importantes entre as decisões individuais e as decisões coletivas aferidas a partir das preferências individuais. Uma delas, que é mais conhecida como efeito ou paradoxo de Condorcet (1743-1794), constitui a referência básica deste trabalho. Tal efeito, quando ocorre, questiona a racionalidade da decisão coletiva a partir da exibição de uma intransitividade após o cômputo da preferência coletiva a partir de preferências individuais transitivas (do mesmo modo que a racionalidade do indivíduo é questionada quando este exibe uma intransitividade em suas preferências).

Outras diferenças mais visíveis existem, como a distorção em proveito próprio (2) das decisões coletivas executadas pelos representantes eleitos pela comunidade. Uma terceira diferença se dá pelo fato da informação necessária para a tomada da decisão nem sempre estar disponível a todos os membros da comunidade. Uma quarta diferença pode ainda ocorrer quando a efetivação da decisão coletiva carecer de um centro volitivo equivalente ao do indivíduo e, por essa razão, ser necessário um tempo de percurso para o comando referente à decisão chegar aos órgãos executores. 
Estas e outras diferenças entre as decisões individuais e as decisões coletivas não serão consideradas neste texto.

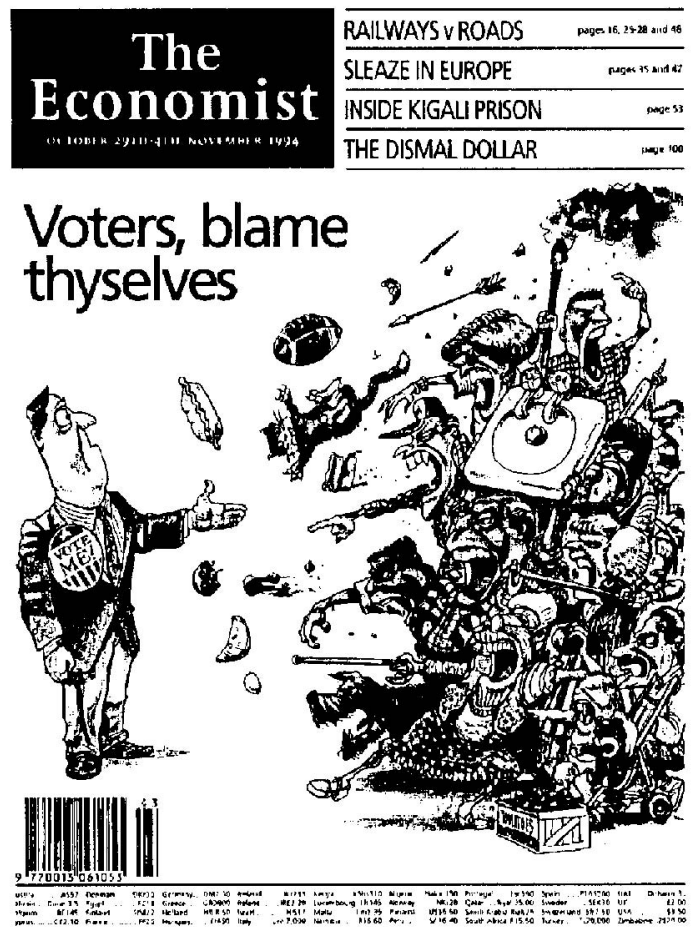

De qualquer modo, o conceito de democracia representativa, pela qual os cidadãos elegem seus representantes e lhes delegam os poderes para legislar e administrar em seu próprio nome, tem sido o paradigma de referência para as Cartas Magnas de muitos países.

Ora, os eleitores, em vários países, não estão satisfeitos com os representantes que elegeram. Tal fato está ocorrendo em vários pontos do planeta onde vige a democracia representativa. A capa de uma revista internacionalmente conhecida ilustra o fato com uma charge que reproduzimos.

Os analistas e comentaristas políticos constatam e interpretam o fenômeno (3). As reações dos políticos e dos eleitores é variada. O candidato Ross Perot, no pleito presidencial de 1992 nos Estados Unidos, orgulhava-se de não ser um político profissional antes de retirar a sua candidatura, que se opunha tanto ao partido democrático quanto ao republicano.

Entre nós, um dos candidatos a governador de São Paulo em 1994, Francisco Rossi, dizia-se apolítico, apartidário e até sem programa, como se fosse algo louvável, porque imaginava que tal aspecto lhe angariaria um número maior de eleitores.

Uma manchete de jornal dizia que "Desconfiança levou ao voto de protesto" e acrescentava que " $39 \%$ dos eleitores votaram em branco ou nulo por não confiar nos candidatos ao governo de São Paulo (4).

O eleitor reagiu engrossando os votos dos candidatos de direita que, matreiramente, se diziam acima da classe política, como Le Pen na França, e o nosso próprio Enéas, que em 94 obteve 15 vezes mais votos do que em 89 (5), apesar de candidatos e seus correlegionários do Prona terem feito elogios a Hitler (6).

Os políticos tentam recuperar a credibilidade do sistema com reformas. Em 2 de novembro de 1994, a Câmara dos Deputados do Japão, aprovava a mais ampla reforma no sistema eleitoral do país desde 1925, cujo objetivo era o de encerrar uma era de instabilidade política iniciada nos anos 80 , na qual diversos governos caíram em meio a acusações de corrupção (7). Na França, 29 membros ou ex-membros do parlamento foram indiciados ou condenados por corrupção (8). 
$\mathrm{Na}$ Itália a corrupção derrubou toda uma classe política e condenou dois exministros a prisão $(9)$.

Um dos resultados do descontentamento e desesperança dos eleitores é o alto grau de abstenção nos países onde o voto não é obrigatório: $50 \%$ na Índia, $48 \%$ no México e $45 \%$ nos Estados Unidos (10).

As reformas propostas para recuperar o entusiasmo dos eleitores pela democracia representativa parecem ser insuficientemente radicais. Uma nova idéia parece ganhar corpo: a democracia direta, tão antiga como a pólis grega.

Nos últimos 200 anos, com exceção da Suíça, mais recentemente da Austrália e de alguns locais dos Estados Unidos, a democracia representativa tem significado um sistema pelo qual o povo vota apenas uma vez, em cada período de alguns anos, para eleger um punhado de representantes que, nesse intervalo, toma todas as decisões importantes em seu nome. A idéia de referendos mais freqüentes é levantada.

Um ensaio (11) propõe nova emenda constitucional para garantir que qualquer petição com um milhão de assinaturas possa ser capaz de acionar um referendo nacional. O referido ensaio afirma que a democracia direta daria aos governadores maior controle sobre os governantes, promoveria a educação cívica e forçaria os políticos a ver os eleitores mais como parceiros do que como mera audiência.

A combinação das tecnologias do computador, do telefone e da televisão, cada qual acrescida das capacidades das demais, está criando graças à sinergia desta integração, uma mudança qualitativa em várias práticas sociais e culturais. Uma dessas alterações, a substituição da democracia representativa pela democracia direta, tem sido anunciada por vários autores que se dedicam a análises globais (12), e comentadores que escrevem em revistas conhecidas (13).

Por que não efetuar os referendos populares acerca de determinados temas já que os recursos da telemática tornam possível e agilizam tal procedimento? De qualquer forma o grande salto eletrônico dos anos 90 dificultará enormemente a conservação da operacionalidade dos procedimentos democráticos no seu estágio atual.

Em 1994, o vice-presidente dos Estados Unidos falou em "forjar uma nova idade ateniense da democracia". Resistências às mudanças certamente ocorrerão, sobretudo por parte dos políticos profissionais uma vez que a implantação da democracia direta erodirá o seu poder, mesmo porque nem todos os temas, sobretudo os mais carregados emocionalmente são adequados à decisão por referendos populares.

O mal estar generalizado do eleitor extravasa para a classe de seus representantes, que afinal dele depende. Este fato tem ocasionado uma predisposição e aguçado a sensibilidade dos políticos para reformas menos radicais do que a implementação da democracia direta, como variações sobre os critérios de escolha dos deputados (sistema distrital e proporcional) e controle do financiamento das campanhas. 
As mazelas que a democracia representativa tem exposto em vários países como a corrupção dos representantes eleitos, a existência de grupos lobistas com grande poder e disposição para o suborno, sugerem mudanças como a já mencionada do Japão.

Entre nós, políticos de renome têm defendido a mudança do sistema eleitoral vigente no Brasil: de voto proporcional uninominal, pelo voto distrital, puro ou misto (14).

Um grupo de estudos, tendo como expositores vários parlamentares e cientistas políticos, debateu questões relativas aos partidos políticos e financiamento de campanhas eleitorais (15). Suas sugestões incluem uma fórmula de transição para a introdução do voto distrital e a lista fechada para o voto proporcional.

Segundo uma manchete de jornal (16), "A USP propõe que cada eleitor valha por dois". Esta é uma maneira hiperbólica de descrever o chamado voto alternativo, no qual, na versão proposta pelo grupo de estudos reunido no IEA, "O eleitor teria direito a dois votos por meio dos quais expressará suas primeira e segunda preferências, que serão computadas com igual valor. Só haverá segundo turno se nenhum dos candidatos, mesmo neste sistema, obtiver a maioria absoluta".

Será possível detectar, no descontentamento do eleitor, nos comentários dos estudiosos e nas várias propostas de reforma dos sistemas eleitorais, alguma razão subjacente inerente ao próprio processo de aferição da vontade coletiva? Afinal, em que se baseia tal aferição a partir do voto dos membros da coletividade?

\section{Modos de aferir a vontade coletiva}

Quando as formas democráticas de governo procuram um meio de legitimar a alocação da posse do poder através de sua confirmação por meio do aval da vontade coletiva, o voto livre e universal é um dos métodos mais importantes para se atingir esta finalidade.

Como se pode, no entanto, estabelecer regras que devam ser seguidas para se compor as preferências pessoais de cada indivíduo a fim de se aferir adequada e legitimamente a preferência coletiva?

A diversidade das culturas e dos contextos políticos conduziram a uma larga variedade de sistemas de votação. Um dos meios mais simples para aferir a vontade coletiva, por meio do voto, é o método pluralista, no qual o candidato que recebe o maior número de votos, vence. Tal sistema oferece sérios inconvenientes. Imaginemos uma disputa entre meia dúzia de candidatos: um deles consegue $20 \%$ dos votos e os cinco demais obtêm aproximadamente $16 \%$ dos votos cada um. Neste caso, pelo método pluralista, o primeiro vence apesar de ter alcançado apenas $20 \%$ da preferência contra $80 \%$ divididos entre os demais, porém contra a sua candidatura. O fato pode provocar instabilidade política e constituiu uma das razões alegadas pelos golpistas no Chile para depor Allende, que nas eleições de 1972 obtivera menos de $40 \%$ dos votos contra dois outros candidatos. O sistema do segundo turno é adotado em muitos países para evitar tal inconveniente. 
Um segundo método é o da regra da maioria, o qual requer que o vencedor tenha mais de $50 \%$ dos votos. É o sistema brasileiro vigente após a Constituição de 1988 para os cargos executivos. Mas a regra majoritária somente garante maioria quando existem apenas dois candidatos, daí a razão do segundo turno quando, numa eleição de mais de dois candidatos, nenhum conseguir mais da metade dos votos válidos (ou totais), conforme a legislação em vigor.

Existe um sistema perfeito? Estudos realizados nos últimos 50 anos revelam que resultados indesejáveis podem ocorrer qualquer que seja o sistema escolhido.

A legitimidade das decisões coletivas aferidas por procedimentos democráticos depende, de modo óbvio e fundamental, de um conceito matemático simples: o conceito de maioria. Eliminando o evento pouco provável de empate, em qualquer escolha dicotômica, um dos lados deve receber mais da metade dos votos. Quando há três (ou mais opções), como já vimos, de força aproximadamente igual, é pouco provável que a apuração indique uma maioria decisiva.

Se cada dimensão do espaço político (17) for representada por uma escala linear, qualquer que seja a curva de distribuição dos eleitores (18) a posição ótima para o candidato é a mediana: o ponto que divide o eleitorado em dois campos de igual tamanho.

Consideremos uma disputa entre dois candidatos aferidos pelo eleitor na tradicional dimensão esquerda-direita do espaço político. Um deles adota a posição um pouco a esquerda da mediana e o outro candidato começa com a posição no meio da porção, à direita da mesma mediana. Tal configuração será típica de um candidato centrista "C" disputando com um candidato moderadamente de direita "D". Neste caso, é lícito se supor que, ao menos nesta dimensão do espaço político, os eleitores cuja preferência estiver à esquerda da posição mantida pelo candidato centrista "C", votarão em "C"; os eleitores cuja posição for à direita de "D", votarão em "D". Aqueles cuja posição estiver entre os dois candidatos, dividirão seus votos entre ambos. Nessas condições, numa pesquisa de intenção de voto, o candidato centrista "C" receberá a maioria dos votos. Tal aspecto é demonstrado graficamente na figura la, na qual a área circunscrita pela curva de frequiência (supostamente normal) é proporcional ao número de votos.

O único modo que " $D$ " teria de melhorar sua posição (nessa dimensão) seria mudá-la em direção ao centro para assegurar mais eleitores à sua direita. Mover sua posição para o centro ou para a esquerda seria sempre vantajoso para o candidato direitista. De modo semelhante, o candidato esquerdista poderia melhorar sua posição movendo-se para o centro ou para a direita, desde que evitasse a entrada de um terceiro candidato mais a sua esquerda.

É claro que não há nada de novo nesta análise. Ela faz parte das táticas mais utilizadas por candidatos (19). Os candidatos representando a direita ou a esquerda tendem a começar sua campanha nitidamente à esquerda ou à direita e se moverem progressivamente para o centro na medida que tentam conquistar um número maior de eleitores, pelo menos em tempos ou situações em que ainda predomina a dimensão tradicional esquerda-direita no espaço político. 
Mas o apelo à posição mediana numa disputa entre dois candidatos os torna vulneráveis a um terceiro candidato de um ou de outro lado. Em qualquer disputa entre dois candidatos próximos ao centro, um terceiro candidato entrando à esquerda ou à direita pode vencer. Em verdade, para praticamente qualquer distribuição do eleitorado, não existem posições nas quais, numa disputa entre dois candidatos, pelo menos um deles não possa ser derrotado por um terceiro. $\mathrm{Na}$ ilustração da figura $\mathrm{lb}$ há sempre uma posição num continuum unidimensional, na qual um candidato recém-chegado "X" (mais à esquerda de "C") ou " $Y$ " (mais à direita de "D") pode se colocar numa posição em que consegue deslocar um candidato mais próximo.

Uma dimensão única nem sempre joga papel decisivo numa eleição. Conformar uma plataforma vencedora em determinado espaço político pluridimensional é tarefa complexa, porque, inclusive, pode ocorrer uma anomalia conhecida por maioria cíclica, percebida desde o final do século XVIII como o, já mencionado, efeito Condorcet.
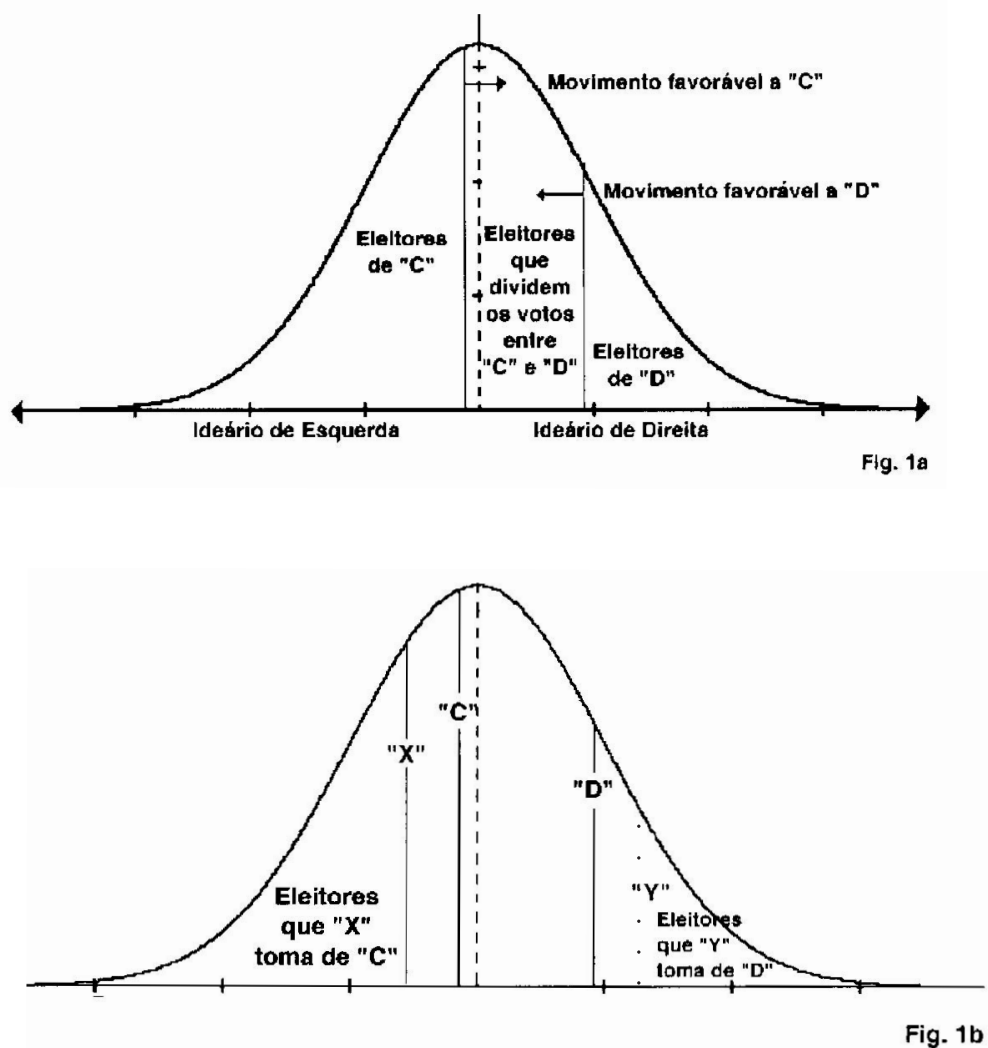

Tal efeito ou paradoxo está articulado na questão da transitividade das preferências, condição indispensável à própria racionalidade do processo de tomada de decisão (20). Se João prefere maçãs a pêras e estas a laranjas, conclui-se que prefere maçãs a laranjas. 
O efeito de Condorcet, como já dissemos, denuncia uma irracionalidade (intransitividade) da decisão coletiva, apurada do cômputo da somas das decisões individuais transitivas.

Imaginemos, num exemplo extremamente simples, três candidatos a determinado cargo eletivo e três ordens de preferência:

$\begin{array}{lll}\text { Eleitor 1 } & \text { Eleitor 2 } & \text { Eleitor 3 } \\ \mathrm{A}>\mathrm{B}>\mathrm{C} & \mathrm{B}>\mathrm{C}>\mathrm{A} & \mathrm{C}>\mathrm{A}>\mathrm{B}\end{array}$

Vemos que "A" ganha de "B" e "B" ganha de "C" por dois votos a um. A intransitividade está em que "C" também ganha de " $\mathrm{A}$ " por dois a um.

Em casos semelhantes, situação também chamada de maioria cíclica, a ordem da votação (numa disputa dois a dois) pode alterar o resultado. No caso mencionado, suponhamos duas disputas seqüenciais dois a dois com as três alternativas possíveis:

$\begin{array}{llll}\text { Ordem da preferência: } & \text { Eleitor } \mathrm{n}^{\circ} \mathrm{l} & {\text { Eleitor } \mathrm{n}^{\circ} 2} & {\text { Eleitor } \mathrm{n}^{\circ} 3} \\ & \mathrm{~A}>\mathrm{B}>\mathrm{C} & \mathrm{B}>\mathrm{C}>\mathrm{A} & \mathrm{C}>\mathrm{A}>\mathrm{B}\end{array}$

Ordem da disputa:

$\begin{array}{llll}\text { Primeira } & \text { AxC } & \text { BxC } & \text { AxB } \\ & \text { C ganha } & \text { B ganha } & \text { A ganha } \\ \text { Segunda } & \text { CxB } & \text { AxB } & \text { AxC } \\ \text { Resultado final } & \text { B ganha } & \text { A ganha } & \text { C ganha }\end{array}$

A determinação do vencedor dependerá da formatação da agenda, que indicará qual a primeira disputa entre as três alternativas possíveis. Em cada caso, a votação é resolvida por dois votos a um. Daí se constata a importância da instância encarregada de agendar a ordem das votações.

Este fenômeno permite o chamado voto útil ou voto estratégico. Assim, se o eleitor $\mathrm{n}^{\circ} 2$ prefere o candidato "C" a "A", e a ordem da votação começa com a disputa $\mathrm{BxC}$, o eleitor, sabendo de antemão, que nesta ordem, o candidato "A" ganha, muda seu voto para "C" (apesar de preferir "B"), a fim de que, no final da disputa ganhe "C" (evitando a vitória de "A").

O voto útil ou estratégico nem sempre é perverso. Suponhamos três candidatos "X", "Y" e "Z" a uma vaga no Senado, numa eleição plural de um só turno. Se, por exemplo, "X" e "Y" forem de centro esquerda, " $Z$ " de centro direita e as pesquisas de intenção de voto derem as indicações: " $X$ " $=25 \%$ " $Y "=35 \%$ " $Z$ " $=40 \%$, será vantajoso para os eleitores de "X" descarregarem seus votos em "Y", que os desagrada menos do que "Z", ao menos na dimensão ideológica. Pode ser demonstrado (21) que, se uma alternativa derrotar todas as demais, numa votação dois a dois, ela será necessaria-mente vencedora através do voto útil. 
A intransitividade característica do efeito Condorcet pode ocorrer na decisão coletiva, mas não na individual; porque a dimensão predominante no espaço de escolha pode variar de eleitor para eleitor, mas é invariável no eleitor individual. A transitividade nas escolhas do eleitor individual é condição indispensável para atribuirmos coerência ao seu processo decisório.

João pode preferir maçãs a pêras e estas a laranjas, segundo uma equação própria na qual predominaria uma dimensão, por exemplo, o sabor. Mas Pedro pode preferir laranjas a maçãs segundo uma outra dimensão, o preço, levando menos em conta o sabor.

Jean Antoine Caritat de Condorcet nasceu em 1743 Cedo revelou sua paixão pela matemática a qual será o eixo de sua reflexão sobre a sociedade. Aos 26 anos é nomeado para a Academia de Ciências.

É eleito para a Convenção republicana em 1791 mas sua prisão é decretada em 8 de julho de 1793 . Vive oculto, quando redige o seu Equisse d'un tableau des progrès de l'espirit humain. Descoberto e preso em 28 de março de 1794, morre nesse mesmo dia na prisão de Bourg-la-Reine.

Condorcet descobriu o efeito que leva seu nome, no qual prova como é dificil extrair uma opinião coletiva a partir de opiniões individuais. Assim, se pedirmos a um eleitor para indicar sua ordem de preferência entre três candidatos $A, B$ e $C$ a opinião majoritária que decorre pode ser incoerente, isto é cíclica. Este é o efeito Condorcet, assim exemplificado pelo próprio autor (CONDORCET, Matemáticas y sociedad, em RASHED R. (org.)): "... Examinemos o voto de 60 eleitores que exibem a seguinte preferēncia:

23 c l a preferência: $A>B, B>C, A>C$, isto é: $A>B>C$

$0 \mathrm{cl}$ a preferência: $A>C, C>B, B>C$, isto é: $A>C>B$

$2 \mathrm{cl}$ a preferência: $B>A, A>C, B>C$, isto é: $B>A>C$

$17 \mathrm{cl}$ a preferência: $B>C, C>A, B>A$, isto é: $B>C>A$

$10 \mathrm{cl}$ a preferência: $C>A, A>B, C>B$, isto é: $C>A>B$

$8 \mathrm{c}$ a preferência: $C>B, B>A, C>A$, isto é: $C>B>A$

Este escrutinio revelará que:

Por 33 votos contra 27 - A é preferido a B

Por 42 votos contra $18-B$ é preferido a $C$

Por 35 votos contra 25 - C é preferido a A..."

Isto significa tanto que $A$ como $B$ ou $C$ obtém a maioria dos votos. Esta contradição, que é o mencionado efeito Condorcet, mostra a intransitividade da opinião coletiva expressa na fórmula. $A>B>C>A$
Suponhamos a dimensão tradicional do espaço político esquerda-direita e, segundo tal dimensão, três candidatos: "L", "C" e "M". Podemos imaginar que, nesta dimensão, os esquerdistas teriam a ordem de preferências $\mathrm{L}>\mathrm{C}>\mathrm{M}$; os direitistas, a ordem $\mathrm{M}>\mathrm{C}>\mathrm{L}$; os do centro dividir-se-iam segundo suas inclinações entre $\mathrm{C}>\mathrm{M}>\mathrm{L}$ e $\mathrm{C}>\mathrm{L}>\mathrm{M}$. Não será possível, porém, imaginar nesta dimensão eleitores que tivessem as escalas de preferência $\mathrm{L}>\mathrm{M}>\mathrm{C}$ ou $\mathrm{M}>\mathrm{L}>\mathrm{C}$.

A eventual ocorrência dessa ordem de preferência indicaria que $\mathrm{o}(\mathrm{s})$ respectivo(s) eleitor(es) teria $(\mathrm{m})$ votado segundo uma dimensão diversa da dimensão esquerda-direita. Não é difícil de se verificar tal aspecto, pois o paradoxo desaparece no momento em que se impõe uma unidimensionalidade ao exemplo formulado pelo próprio Condorcet (22).

A intransitividade que pode ocorrer quando se computa a decisão coletiva através da soma dos votos dos indivíduos coloca um ranço de irracionalidade no resultado do procedimento. Como evitá-lo?

Vários procedimentos de votação têm sido propostos, inclusive com o intuito de evitar o aparecimento do efeito Condorcet. Tal paradoxo (intransitividade da preferência coletiva apurada a partir da soma de preferências individuais transitivas) preocupou matemáticos, lógicos e cientistas políticos desde o século XIX, inclusive Lewis Carrol, o autor de Alice no País das Maravilhas.

No voto por aprovação, também chamado de voto alternativo, o eleitor marca na cédula cada candidato que tem a sua aprovação. O candidato com o maior número de votos é eleito. Nesse sistema, nunca é vantagem para o eleitor reprimir 
o voto para sua primeira escolha, direcionando-o a outro candidato com sua menor preferência (voto útil ou estratégico). Se todos os candidatos tiverem igual chance de vitória, o eleitor votará naqueles que preferir. Votar em maior número de escolhas dará apoio a candidatos rejeitados; votar em menor número, (digamos apenas na primeira escolha), arriscará a vitória de um candidato inaceitável. O voto de aprovação tem sido descrito como: um eleitor, $n$ votos. A descrição é adequada porque o eleitor pode votar em cada candidato aceitável. Torna, inclusive, menos freqüente a necessidade do segundo turno para garantir a legitimidade da maioria dos votos (23).

A votação por segundo turno (runoff) seleciona para uma segunda eleição os dois candidatos mais votados na primeira. O sistema garante a maioria de $50 \%$ a um dos candidatos e é adotado em muitos países, inclusive no Brasil, nas eleições para cargos executivos.

No sistema de votação por pontos, o número de votos dados à primeira escolha é multiplicado por um coeficiente, digamos "n"; a segunda escolha por "n-1", e assim sucessivamente.

No sistema por voto plural, o candidato que receber o maior numero de votos é eleito, obtenha ou não a maioria de $50 \%$ mais um de votos. Tal sistema tem o inconveniente de não garantir a legitimidade ao candidato vencedor. Muitos países, para contornar o fato, deixam a decisão final de escolha entre os mais votados a cargo do Congresso. Em determinados casos, os resultados dos vários sistemas já mencionados não coincidem. Um exemplo didático pode ilustrar tal fato. Suponhamos que 27 vereadores da câmara de uma cidade devam escolher entre três alternativas para executar melhoramentos em seus municípios: "A" construir um posto de saúde; "B" edificar uma escola primária; "C" recapear uma estrada municipal. A ordem de preferência dos 27 vereadores com relação a essas opções obedeceria ao esquema 11 vereadores $=\mathrm{A}>\mathrm{B}>\mathrm{C} ; 9$ vereadores $=\mathrm{B}>\mathrm{C}>\mathrm{A} ; 7$ vereadores $=\mathrm{C}>\mathrm{A}>\mathrm{B}$.

Desse ordenamento conclui-se que: a opção "A" é preferia à "B" por $11+7=18$ votos contra 9; a opção "B" é preferia à "C" por $11+9=20$ votos contra 7 ; a opção "C" é preferida à “A" por 9+7=16 votos contra 11 .

Ocorre o já mencionado fenômeno da maioria cíclica, no qual qualquer das três opções obtém a maioria. Consideremos a seguinte decomposição das preferências:

\begin{tabular}{|c|c|c|c|c|c|}
\hline \multirow[b]{2}{*}{$\mathrm{A}>\mathrm{B}>\mathrm{C}$} & \multicolumn{2}{|l|}{ Total } & \multicolumn{2}{|c|}{ Apenas $1^{\mathrm{a}}$ escolha } & $1^{\mathrm{a}}$ e $2^{\mathrm{a}}$ escolhas \\
\hline & 8 & 4 & (Apenas A) & 4 & $(\mathrm{~A}$ e $\mathrm{B})$ \\
\hline $\mathrm{A}>\mathrm{C}>\mathrm{B}$ & $3(11)$ & 3 & (Apenas A) & 0 & $(\mathrm{~A}$ e C $)$ \\
\hline $\mathrm{B}>\mathrm{A}>\mathrm{C}$ & 5 & 4 & (Apenas B) & 1 & $(\mathrm{~B}$ e A) \\
\hline $\mathrm{B}>\mathrm{C}>\mathrm{A}$ & $4(9)$ & 4 & (Apenas B) & 0 & $(\mathrm{~B}$ e C $)$ \\
\hline $\mathrm{C}>\mathrm{A}>\mathrm{B}$ & 2 & 1 & (Apenas C) & 1 & $(\mathrm{C}$ e A $)$ \\
\hline $\mathrm{C}>\mathrm{B}>\mathrm{A}$ & $5(7)$ & 4 & (Apenas C) & 1 & $(\mathrm{C}$ e B $)$ \\
\hline
\end{tabular}


No sistema de voto plural o resultado seria "A" = 11; "B" = 9; “C" = 7; com a conseqüente vitória de "A".

No sistema de segundo turno, "A" enfrentaria "B" com a eliminação de "C". Nos votos da ordem de preferência $\mathrm{C}>\mathrm{A}>\mathrm{B}, \mathrm{A}>\mathrm{B}$ são 2 ; nos votos da ordem $\mathrm{C}>\mathrm{B}>\mathrm{A}$, $B>A$ são 5. Portanto, o resultado da votação seria: "A": $11+2=13$; "B": $9+5=14$, com a conseqüente vitória de " $B$ ".

Outro sistema, chamado de Borda, seria o de alocar pesos proporcionais à ordem de preferência. Assim, por exemplo, o primeiro lugar teria o coeficiente 3 , o segundo 2 , e o terceiro 1 .

A sua aferição computaria: pontos de "A": $(11 \times 3)+(7 \times 2)+9=56$; pontos de "B": $(9 \times 3)+(13 \times 2)+5=58$; pontos de "C": $(7 \times 3)+(7 \times 2)+13=48$, com a conseqüente vitória de "B".

Um quarto sistema seria o da aprovação. Nele são aferidas a primeira e a segunda opções. O resultado seria "A": $11+1+1=13$; "B": 9+4+1=14; "C": 7 com a conseqüente vitória de " $\mathrm{B}$ ".

Verificamos aqui, que quando ocorre a maioria cíclica, os resultados podem eventualmente variar conforme o sistema adotado para a aferição dos votos. Existirá um sistema melhor do que os outros?

Tal problemática refere-se essencialmente à questão de se saber como podem ser estabelecidas regras a serem seguidas para se compor as preferências individuais de cada elemento de um grupo ou coletividade, procedimento essencial para qualquer regime ser considerado democrático. Em suma, qual a alquimia que pode transformar, com aceitação geral, as preferências individuais numa decisão coletiva?

Esse problema, que a partir da descoberta de Condorcet se tornara aflitivo para os cientistas políticos e sociais, foi formulado com precisão por Keneth Arrow, ganhador do prêmio Nobel de economia de 1972. Arrow enunciou cinco condições fundamentais (24), essenciais a todo o regime democrático. Tais condições são consideradas pela maior parte dos especialistas como exigências perfeitamente razoáveis para qualquer procedimento de tomada de decisão coletiva que se fundamente em preferências individuais expressas por meio do voto.

Arrow demonstra, todavia, que é impossível fazer prevalecer a vontade da maioria sem infringir uma das cinco condições por ele enunciadas. Tal paradoxo provocou considerável impasse no seio das ciências políticas, impasse que foi considerado por alguns autores (como o economista Paul Samuelson) como equivalente aos teoremas de inconsistência de Kurt Godel, que tinham abalado os fundamentos da matemática (25).

A problemática de Arrow, cuja origem é o paradoxo de Condorcet, preocupa sobretudo os estudiosos de ciência política. Condorcet acreditava que o desenvolvimento científico e os procedimentos democráticos de governo promoveriam o progresso moral e material da sociedade demonstrando, ao mesmo tempo, que 
a vontade coletiva expressa pelo voto pode se mostrar intransitiva e conter, portanto, um elemento de irracionalidade. Condorcet estendeu a crença absoluta na razão e no processo científico aos assuntos humanos. A sociedade, para ele, também deveria ser regida pelo modelo da física newtoniana (26): “... Todos os erros na política e na moral são baseados em erros filosóficos e estes, por sua vez, conectados a erros científicos ...".

É este filósofo iluminista, adepto convicto da razão universal como instrumento da maioridade e liberação do homem que, paradoxalmente, deduz um fator de irracionalidade no processo de transferir as vontades individuais livremente dispostas à vontade coletiva. É a questão da intransitividade. Pode-se indagar se as cinco condições de Arrow, impossíveis de serem obedecidas simultaneamente, constituem na prática um obstáculo tangível à transferência adequada e racional do voto individual à vontade coletiva.

Existe uma bem conhecida condição que evita a ocorrência do paradoxo do voto: o fenômeno da existência do chamado pico máximo, apontado por Duncan Black (27) nos anos 40. Ocorre usualmente quando candidaturas (em eleições) e temas (em comitês) são avaliados segundo um único critério ou dimensão.

A condição de pico único e sua relação com o paradoxo do voto constituiu importante descoberta. Sugere que o paradoxo do voto ocorre, na prática, com menor freqüência do que se poderia supor (28).

Se os eleitores comungam um quadro de referência comum na análise de determinada questão, suas preferências se organizarão segundo um pico único, não importando quanto eles possam diferir no interior dessa dimensão. A existência de uma dimensão única evita a ocorrência do paradoxo. Qual a relação destas considerações teóricas com a já mencionada crise atual da democracia representativa?

\section{As mudanças do espaço político}

Como já visto, a freqüência do paradoxo do voto é menor quando as escolhas são, em sua maioria, unidimensionais, como, por exemplo, as efetuadas segundo a dimensão esquerda-direita ou liberal-conservadora que têm prevalecido em vários países desde o século passado.

Com a queda do muro de Berlim e a transformação das repúblicas do Leste europeu, onde imperava o socialismo real em repúblicas pluralistas, a dimensão ideológica esquerda-direita, eixo da chamada Guerra Fria, tem perdido a intensidade que possuía e temas mais locais ou limitados a determinados países têm prevalecido. A tradicional dimensão esquerda-direita perdeu, em muitos países, parte de sua importância histórica como divisor de águas entre os eleitores.

Novas dimensões surgem no espaço político: políticas relacionadas à integração das minorias nos países europeus; estatismo versus privatização (em termos pragmáticos); políticas de partidos verdes; lutas étnicas ou religiosas; temas mais paroquiais que substituem os grandes debates ideológicos. 
Ora, como vimos, a substituição de uma dimensão privilegiada do espaço político por outras mais fragmentadas favorece o aparecimento do efeito Condorcet. As características do eleitor racional, cujo atributo individual é a transitividade de suas preferências pode, ao ser transferida à vontade coletiva, resultar em intransitividade quando as dimensões do espaço político se multiplicam em demasia.

Uma das maneiras de se evitar tal fragmentação do espaço político em múltiplas linhas de força, algumas incomunicáveis entre si ou não redutíveis a um denominador comum e, conseqüentemente, favorecendo o aparecimento do paradoxo das votações, é a redução do número de partidos políticos. Os partidos (e é esta justamente uma de suas funções) devem determinar certas dimensões privilegiadas no espaço político. Em torno delas devem ser travados os debates e matrizados os conflitos. Desse modo, é reduzida a possibilidade de escolha do eleitor ocorrer segundo dimensões incompatíveis.

Tal problemática afeta os países de maneira diversa. Entre nós, sem dúvida, há número excessivo de partidos. A sua redução, longe de ser danosa como pretendem demonstrar alguns cientistas políticos (29) com argumentos apenas retóricos, tornaria os resultados das eleições mais palatáveis e compreensíveis.

É possível (esta é apenas uma hipótese) que o desengano com o sistema representativo, já mencionado, além de razões de natureza econômica e social, possa encerrar em seu bojo um sentimento latente de frustração devido à emergência da intransitividade e conseqüente fator de irracionalidade na aferição da vontade coletiva: a emergência do efeito Condorcet e, como conseqüência, o paradoxo do voto.

Se o esvaziamento relativo da dimensão tradicional esquerda-direita ocorre em países com sólida tradição de política partidária, no Brasil, onde os partidos, com algumas exceções, não possuem clara tradição nessa dimensão, a situação, as composições e as alianças em nível nacional e, mais ainda, em nível regional, mostram (30) a existência de múltiplas dimensões por meio das quais o eleitor brasileiro escolhe os seus candidatos. Desenhar as principais linhas de força, diretrizes e características de tais dimensões é tarefa das mais importantes da pesquisa da ciência política entre nós.

Esse dado empírico deve preceder à reforma eleitoral já anunciada, pois o número de partidos políticos deve ter correlação com as principais linhas de força do espaço político. Como viabilizar um sistema representativo que possa tornar mais adequada e legítima a aferição da vontade coletiva? Como matrizar o espaço político em linhas de força de modo a evitar a emergência de fenômenos do tipo efeito de Condorcet?

Essas e outras indagações e questões deverão ser devidamente equacionadas para que se possa pensar num novo código eleitoral, talvez combinando instâncias de democracia representativa com outras formas, como por exemplo, a de democracia direta.

É possível que uma nova e mais adequada forma de aferir a vontade coletiva 
por meio do voto individual possa reduzir algumas das tensões derivadas do fato de o eleitor se sentir mal representado em seus verdadeiros anseios, opiniões e atitudes. Dentro da complexidade das questões que afligem nossa sociedade, um pouco mais de racionalidade nos processos de verificação e aferição da vontade coletiva só pode ser útil para se tentar superar a crise da democracia representativa.

\section{Notas}

1 Devemos distinguir entre a vontade de uma comunidade ou população, a qual, na Grécia Antiga, era apurada diretamente pelo voto de todos os cidadãos dados na Assembléia, da distribuição de cargos que, por essa razão, não eram representativos, mas funcionais. Para esta última distribuição, Aristóteles preconizava a alocação por sorteio e não por votos.

2 Algumas das distorções da representação da vontade coletiva foram descritas por Robert Michels, (Les Partis Politiques, Flammarion, 1971). O autor estudou os partidos e sindicatos operários da Alemanha imperial da primeira década deste século. Este estudo datado, realizado há 80 anos, precedeu inúmeros trabalhos sobre as distorções da representação da vontade coletiva.

3 The Economist, 29 out. 1994, p.15-16; 17 jun. 1995, p.13-14.

4 Folha de S. Paulo, 16 out. 1994, 1-19.

5 Id., Ibid., 1-17.

6 Id., 30 ago. 1994, Especial-4.

7 Id., 3 nov. 1994, $2-8$.

8 The Economist, 29 out. 1994, p.16.

9 Folha de S. Paulo, 8 jul. 1995, 2-10.

10 Time, 30 maio 1994, p.9.

11 G. Mulgan \& A. Adonis. Lean democracy. Demos Quarterly, jul. 1994.

12 J. Nasbit. Global paradox. New York, Avon Books, 1994.

13 B. Beedham. A beter way to vote. The Economist, 11 set. 1993, p. 7-10.

14 J. Sarney. Meu nome é 2518 ou Pipil. Folha de S. Paulo, 14 out. 1994, 1-2.

A.F. Montoro. O deputado é quase um fantasma. Folha de S. Paulo, 23 dez. 1994, 1-3.

15 Debates realizados nos dias 16, 23 e 30 de outubro de 1993 na sede do IEA-USP.

16 Folba de S. Paulo, 19 ago. 1993, 1-10.

$17 \mathrm{O}$ conceito de espaço político tem sido definido como a área de conflito que constitui a base da relação entre eleitores e partidos, num dado local e em determinado momento histórico. Como todo o sistema político é caracterizado por certo número de conflitos e divergências que dividem as atitudes e opiniões da população, tais divergências constituirão os eixos das dimensões do espaço político. Nos regimes democráticos de massa, o espaço político identifica-se como o espaço de competição 
eleitoral. O eleitor racional deve ser capaz de avaliar o partido cuja posição está mais próxima da sua própria colocação nesse espaço. As dimensões desse espaço correspondem às principais linhas de conflito numa determinada sociedade e em determinado momento. A dimensão mais usual é a esquerda-direita, que tem representado desde o século passado importante divisor de águas entre os eleitores das democracias representativas. Recentemente dois textos tratam da dimensão esquerda-direita do espaço político: N. Bobbio. Esquerda e direita, Unesp, 1994 e Sader, E. O anjo torto, Brasiliense, 1995.

18 A curva de distribuição dos eleitores tanto pode ser uma curva normal como qualquer outra, uma vez que a mediana é a linha que, por definição, divide os dois campos em partes iguais.

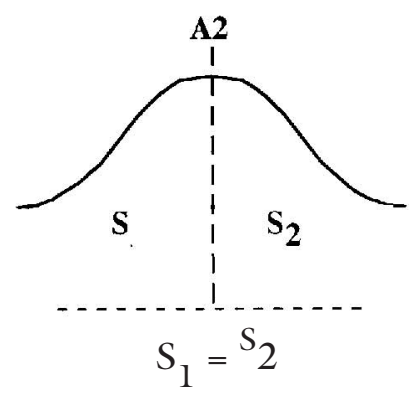

$\mathrm{A}_{1}$

Curva Normal

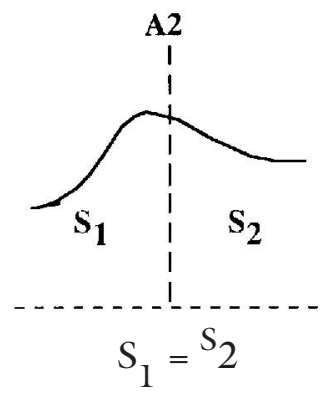

$\mathrm{A}_{1}$

Curva Assimétrica

$\mathrm{A}_{1} \mathrm{~A}_{2}=$ Mediana

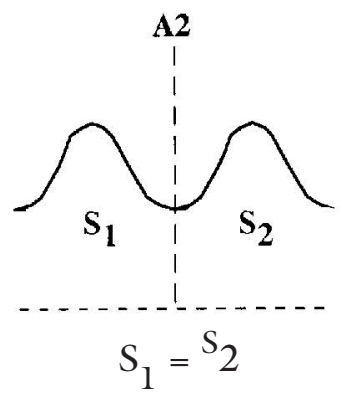

$A_{1}$

Curva Bimodal

19 Noticiário dos jornais anunciava, quando se aproximava a data das eleições presidenciais de 1994, que o candidato Lula deslocava sua posição política para o centro em relação à posição anterior. "Lula quer moderar programa do PT, candidato acha que partido precisa flexibilizar suas propostas para ampliar sua penetração na classe média". Folha de S. Paulo, 3 out. 1994, Especial-5.

20 A decisão ou escolha considerada lato sensu como a possibilidade de ordenar as preferências recobre tanto a decisão individual quanto a decisão coletiva. Esta compreende a teoria dos votos. J. Piaget \& P. Fraisse. Traité de psychologie experimentale, v. VIII, cap. XXIX Les decisions.

21 Por definição, o vencedor Condorceté aquele capaz de vencer todos os outros concorrentes em escolhas duas a duas, isto é, se $\mathrm{n}_{1}, \mathrm{n}_{2} \ldots \mathrm{n}_{\mathrm{m}}$, são candidatos, o vencedor no sistema Condorcet será $\mathrm{n}_{\mathrm{z}}$, se este vencer todas as disputas duais: $\mathrm{n}_{\mathrm{z}} \times \mathrm{n}_{1}, \mathrm{n}_{\mathrm{z}} \times \mathrm{n}_{2} \ldots$ $\mathrm{n}_{\mathrm{z}} \times \mathrm{n}_{\mathrm{m}}$.

22 Consideremos o exemplo dado pelo próprio Condorcet, já descrito, mas com uma escala de preferência unidimensional com a ordem crescente $\mathrm{A}>\mathrm{B}>\mathrm{C}$ ou $\mathrm{C}>\mathrm{B}>\mathrm{A}$ :

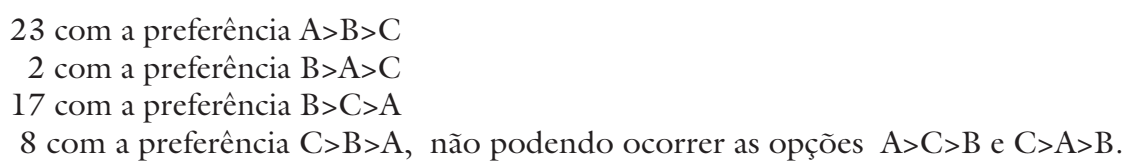


Neste caso:

$\mathrm{B}>\mathrm{A}$ por $(2+17+8)=27$ contra 23

$\mathrm{B}>\mathrm{C}$ por $(23+2+17)=42$ contra 8

$\mathrm{A}=\mathrm{C}$ por $(23+2)=25$ contra $(17+8)=25$

A ordem vencedora seria $\mathrm{B}>\mathrm{A}=\mathrm{C}$ com ausência do efeito Condorcet. São aferidos apenas os 50 votos a adstritos à preferência unidimensional. A ausência deste efeito ocorre com qualquer redistribuição dos 10 votos remanescentes nessa escala unidimensional.

Se a ordem crescente (ou decrescente) fosse, por exemplo, $\mathrm{A}>\mathrm{C}>\mathrm{B}$ ou $\mathrm{B}>\mathrm{C}>\mathrm{A}$, teríamos:

0 com preferência $\mathrm{A}>\mathrm{C}>\mathrm{B}$

17 com preferência $\mathrm{B}>\mathrm{C}>\mathrm{A}$

10 com preferência $\mathrm{C}>\mathrm{A}>\mathrm{B}$

8 com preferência $\mathrm{C}>\mathrm{B}>\mathrm{A}$, na qual, pela unidimensionalidade não poderiam ocorrer as opções $\mathrm{A}>\mathrm{B}>\mathrm{C}$ e $\mathrm{B}>\mathrm{A}>\mathrm{C}$.

Neste caso:

$\mathrm{C}>\mathrm{A}$ por $(10+8+17)$ a 0

$\mathrm{B}>\mathrm{A}$ por 25 a 10

$\mathrm{C}>\mathrm{B}$ por $(10+8)$ a 17 e a ordem vencedora seria: $\mathrm{C}>\mathrm{B}>\mathrm{A}$, também sem o efeito Condorcet.

O mesmo poderia ser demonstrado para qualquer das demais ordens crescente ou decrescente $\mathrm{B}>\mathrm{A}>\mathrm{C}$ ou $\mathrm{C}>\mathrm{A}>\mathrm{B}$.

$23 \mathrm{O}$ voto por aprovação ou alternativo, já mencionado, foi objeto de uma proposta que o cientista político Bolivar Lamounier, coordenador dos estudos IEA-USP, levou à Federação das Indústrias de São Paulo. Cf. Folha de S. Paulo, 19 ago. 1993, 1-10.

24 K.J. Arrow. Social choice and individual values. John Wiley \& Sons, Inc. 1963. Arrow formulou alguns axiomas em seu trabalho, constituídos por cinco condições fundamentais a todo o processo coerente para a determinação da vontade coletiva num regime considerado democrático. Tais condições deveriam ser respeitadas em todo o regime democrático, isto é, naquele no qual a vontade coletiva deveria representar a soma das vontades individuais:

I Abrangência universal: a constituição democrática deve ser capaz de agregar qualquer configuração possível de votos. Não sendo possível predizer todos os padrões de conflitos que podem surgir na vigência da constituição, esta não deve ser infringida quando surgem certas configurações de preferências de votos. A constituição deve, por esta razão, ter abrangência capaz de resolver todas as controvérsias possíveis. Assim, qualquer que sejam as preferências dos membros da coletividade, o procedimento de aferição da vontade coletiva deve ter em conta uma e apenas uma ordem de preferência.

II Unanimidade: a vontade coletiva deve estar de acordo com as preferências de seus membros. Quanto maior o número de pessoas que exprimirem uma determinada preferência, no mesmo grau, a vontade coletiva deve estar de acordo com tal preferência.

III Determinação por pares: a ordenação coletiva de um par de alternativas deve depender apenas das ordenações individuais dessas alternativas, significando que se a vontade coletiva preferir $\mathrm{X}$ a Y (reflexo da soma das vontades individuais), e se as preferências individuais mudarem 
com respeito a outros pares de alternativas $(\mathrm{U}, \mathrm{V}),(\mathrm{A}, \mathrm{B})$ etc. mas se mantiver invariável com relação a X e Y, a preferência coletiva deveria respeitar essa invariança. Tal axioma ou condição pode ser ilustrado pelo exemplo a seguir, no qual se mostra, na abcissa, a escala de preferência de um indivíduo M, e, na ordenada, de outro indivíduo N. Se X é preferido a Y por $\mathrm{M}$ em relação a $\mathrm{N}$ (que prefere $\mathrm{Y}$ a $\mathrm{X}$ ), esta preferência não deve ser alterada pela preferência de $\mathrm{M}$ em relação a $\mathrm{N}$ em relação a qualquer outro par, por exemplo $\mathrm{U}$ e $\mathrm{V}$.

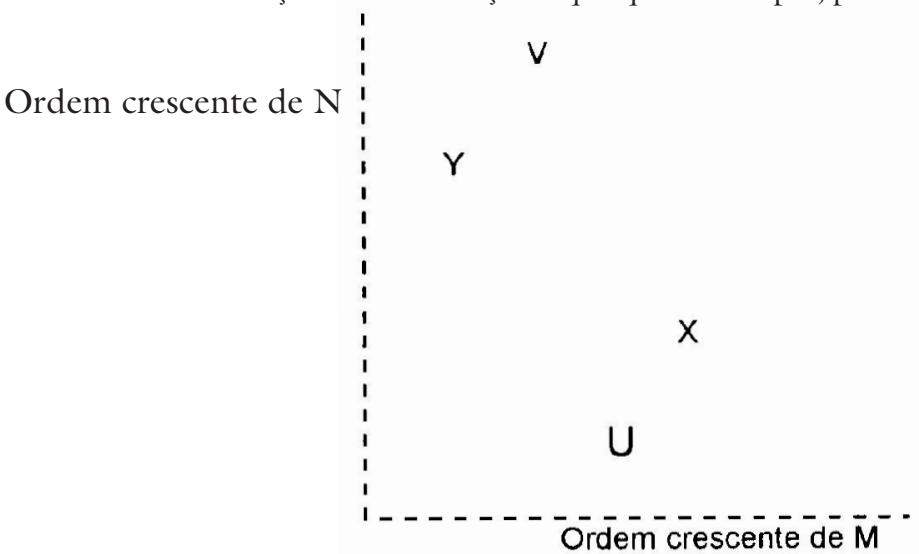

Essa condição pode ser resumida dizendo-se que a escolha de uma coletividade em face a uma alternativa é fundamentada na escolha dos indivíduos diante da mesma alternativa (e de nenhuma outra).

IV A coletividade não deve prejulgar suas escolhas: para duas escolhas, $\mathrm{X}$ e Y, há necessariamente um certo número de preferências individuais possíveis que permitem à coletividade preferir $\mathrm{X}$ a Y.

V Para a coletividade, nenhum individuo prejulga suas escolbas: Arrow admite que as escolhas da sociedade não são idênticas à escolha de qualquer indivíduo isoladamente.

Alguns tipos de práticas de aferição das preferências individuais têm sido propostos para contornar os impasses oriundos de votações com mais de dois candidatos, as chamadas eleições plurais e destinadas a contornar o impasse descrito por Arrow.

25 P. Samuelson., apud M. M. Gardner. On the paradoxical situations that arise from nontransitive relations. Scientific American, outubro de 1974, p.120: “... A busca das grandes mentes, registradas na história, pela democracia perfeita tornou-se a busca de uma quimera, de uma autocontradição lógica... Agora os estudiosos de todo o mundo em matemática, política, filosofia e economia estão tentando salvar o que pode ser salvo da descoberta devastadora de Arrow. Tal descoberta é para a matemática da política o que o teorema de Kurt Godel (1931) da impossibilidade da prova de consistência foi para a lógica matemática...”

26 M.J.N.C. Condorcet. Esquisse d'un tableau historique des progrès de l'espirit humain, 1793.

27 D. Black. The theory of committus and elections. Cambridge, Un. Press, 1958. 
28 Uma linha fértil de pesquisa nessa problemática é a de questionar sob que condições o paradoxo da votação seria inoperante. Uma das possíveis condições é justamente a do pico único (single peakedness). Não obstante os eleitores individuais possam diferir agudamente em sua primeira alternativa, a existência de uma única dimensão sob a qual eles avaliam as alternativas implica usualmente preferências do tipo pico único.

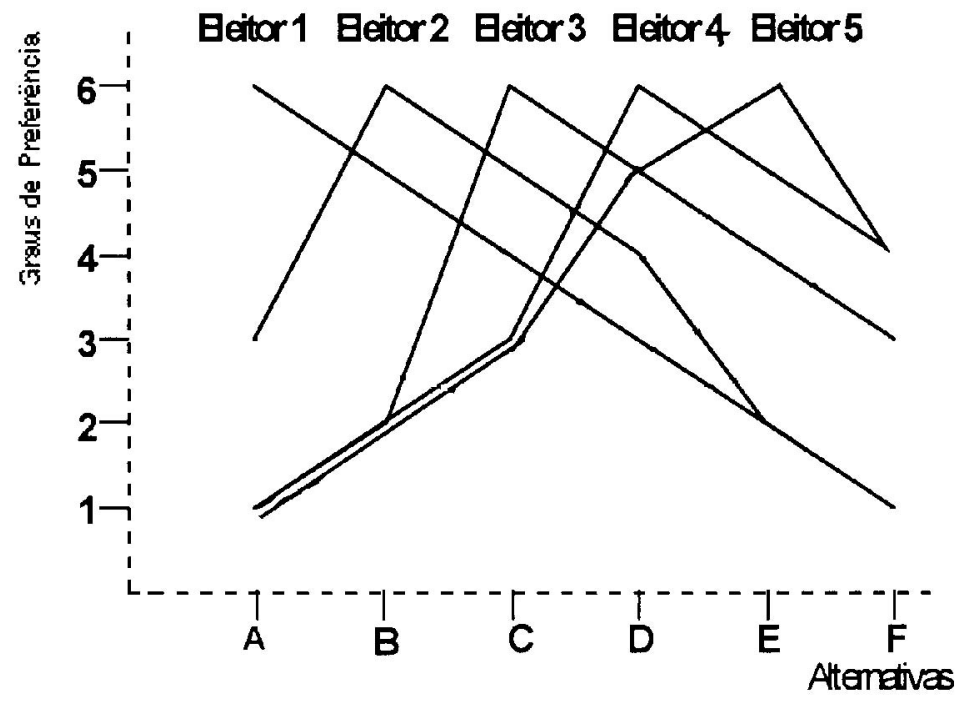

Neste caso, o paradoxo não ocorre, uma vez que o eleitor 3 pode vencer cada um dos outros em competições duais (a existência de um vencedor Condorcet garante a não-ocorrência do paradoxo das votações. G.R. Niemi. \& W.H. Riker. The choice of voting systems. Scientific American, jun. 1976, p. 21/27.

29 E. Lessa, E. A teoria da representação mínima. Folha de S. Paulo, 3 fev. 1995, 1-3.

$302^{\circ}$ turno aumenta confusão de alianças entre partidos. Folha de S. Paulo, 16 out. $1994,1-14$.

Referências bibliográficas

ARROW, K. Social choice and individual values. John Wiley, 1963.

BLAIR, D. H. \& POLLAK, R.A. Rational collective choice. Scientific American, ago. 1983, p. 67-83.

BOBBIO, N. et al. Dicionário de política. Brasília, UnB, 1986.

BOTÃO, P.R. Sistema eleitoral e partidário: a urgência de mudanças. IMS, 1994 [mimeo.]. 
CONDORCET, M.J.N.C. A teoria matemática das eleições. In: RASHED, R. (org.). Matemáticas y sociedad. México, Fondo de Cultura Economica, 1990.

ENELOW, J.M. \& HINICH, M.J. (eds.). Advances in the spatial theory of voting. Cambridge, Un. Press, 1990.

FARQUHARSON, R. Theory of voting. New Haven, Yale Un. Press, 1969.

GRANGER, G.G. La mathématique sociale du marquis de Condorcet. Ed. Odile Jacob, 1988.

LAMOUNIER, B. Partidos políticos e sistema eleitoral. Série Textos Idesp, texto n. 13, 1986.

LAMOUNIER, B. \& MUSZYNSKI. O processo eleitoral brasileiro, da Velha a Nova República. Série Textos Idesp, texto n. 14, 1989.

SHEPSLE, K. Models of multiparty electoral competition. London, Harwood, 1990.

Isaac Epstein é pesquisador da Cátedra Unesco de Comunicação da Universidade Metodista de São Paulo (São Bernardo do Campo, SP).

Trabalho apresentado pelo autor na secção de Política da $20^{\text {th }}$. Scientific Conference of the International Association for Mass Communication Research realizada em agosto de 1996 em Sydney, Austrália. 